\title{
MORFOLOGÍA Y SIGNIFICADO DE LA CAMA EN MARCEL PRÉVOST. DEL LECHO CONYUGAL AL CAMASTRO DEL ADULTERIO
}

\author{
MORPHOLOGY AND MEANING OF THE BED IN THE WORK \\ OF MARCEL PRÉVOST. FROM MARRIAGE TO ADULTEROUS LIAISONS. \\ Jordi LUENGO LÓPEZ \\ Universidad Pablo de Olavide, de Sevilla \\ jluengol@upo.es
}

\begin{abstract}
Resumen: Pese a no ser considerado por la crítica literaria como un autor erótico, Marcel Prévost recurre con frecuencia a la exaltación del amor pasional y a las escenas que la sugieren. En muchas de ellas, la cama será el centro neurálgico de esa amatoria, generada o contenida, alrededor de la cual las mujeres burguesas tamizaban su existencia en el círculo social al que pertenecían. A lo largo del presente estudio profundizaremos en los significados de la cama, yendo desde la sacralidad del lecho conyugal a los camastros improvisados en lugares ocultos para consumar la infidelidad, concibiéndose este mueble de sueño y ensueño como dual representación física de libertad y sujeción entre los individuos.
\end{abstract}

Palabras clave: Marcel Prévost. Cama. Erotismo. París. Señoritas burguesas.

Abstract: Despite not being recognised by the literary critics as an erotic writer, Marcel Prévost frequently invokes the heightening of passionate love and the scenes which depict it. In many of them, the bed was the nexus of that ars amatoria, created or contained, around which Bourgeois ladies sifted their existence within the social circle they inhabited. This paper examines in depth the meanings of the bed, from a sacrosanct marital space to a clandestine mise-en-scene to consummate adulterous liaisons, approaching this piece of furniture, created for sleep and dreams, as a dual physical representation of freedom and subjection between individuals.

Keywords: Marcel Prévost. Bed. Erotism. Paris. Bourgeois ladies.

\section{INTRODUCCIÓN}

Al pensar en un objeto en concreto ha de tenerse en cuenta que, como representación mental asociada a un significante lingüístico, dicho cuerpo inanimado suele ser independiente del significado que se le asigna. La imagen del objeto físico que la mente recrea en función de su percepción visual no depende únicamente de la esencia de éste, 
sino que se conforma en función de un conglomerado de experiencias, impresiones, recuerdos $\mathrm{u}$ otros elementos psíquicos que condicionan al individuo que realiza este ejercicio de captación. Esa imagen queda plasmada en la mente como concepto que se moldea en virtud de los elementos foráneos que en torno a ella van apareciendo, aunque su morfología y estructura física en el plano de lo real sea única para todo aquel ${ }^{1}$ que la observe. Este fenómeno se advierte también en la lectura de un texto literario, dado que, en esta acción, la subjetividad creativa del sujeto-lector concede a ese objeto una serie de características que lo definen en base al marco contextual en el que se manifiesta. En este sentido, el texto suscita el conocimiento abstracto del objeto por la denominación, la descripción o la evocación del mismo, siendo determinante para su representación y consecuente atribución de significado, al margen de que ya se encuentre inicialmente predefinido (Lepaludier, 2004: 34). Una recreación cognitiva que se configura en sintonía con la voluntad demiúrgica de su creador y la proyección que del cuerpo aludido el lector plasma en su psiquis analítica. De este modo, el escritor marca los parámetros interpretativos del objeto en cuestión a lo largo de la narración de aquellas escenas en las que lo introduce, condicionando así el conocimiento que de él tenga el lector y cuestionando el concepto en sí fraguado en su intelecto. Un recurso con el que el autor consigue convertir al objeto físico en el eje conductor de su discurso narrativo al que recurrirá con frecuencia desde distintos prismas para hilvanar la lógica de la ficción relatada.

En la obra de Eugène Marcel Prévost (1862-1941), siguiendo este patrón interpretativo, la cama aparece como idea regulativa que se cierne sobre las relaciones íntimas que entablan sus personajes. Una geometría de rectangular amatoria que no es exclusiva del novelista y dramaturgo francés, sino que siempre ha estado presente en las distintas formas de creación escrita y géneros literarios, aunque con distintos niveles de recurrencia e intencionalidad. Los usos que se le da a la cama según el pasaje que desea contarse varían de acuerdo con aquello que el autor pretende comunicar. La cama puede concebirse entonces como aquel enser cuya descripción complementa al pasaje que se narra, permeabilizándose en él para crear un discurso alternativo desde el que se dice abiertamente aquello que el texto no revela. Así, más allá de su mera utilidad, la cama puede ser el lugar donde reposan las almas atormentadas; allí donde los sueños se incrustan en los espíritus de quienes los crean y donde se consuma la tensión erótica generada entre dos individuos; aquel secreto páramo en el que se gozan y lloran las infidelidades que en su seno se cometen; entre otras calidoscópicas manifestaciones que acaecen en ese lugar donde se nace y, en circunstancias normales, se muere, y donde la noción de tiempo se desvanece para conjurar con esas horas aparentemente perdidas de vida.

La cama se encuentra, por consiguiente, vinculada con lo humano, estando el significado que de ella se desprende relacionado con el empleo que se le dé, pero también

\footnotetext{
${ }^{1}$ Sirva el uso eventual del genérico masculino para referirnos tanto a hombres como a mujeres.
} 
con la morfología del instrumento en sí y el léxico que le acompaña (camastro, litera, yacija, lecho, tálamo, catre, etc.). En ese sentido, resulta oportuno recordar la apreciación que, en 1882, realizaba Guy de Maupassant (1850-1893) en torno a esa estrecha conexión habida entre lo humano y la cama, recurriendo para ello al uso que, según las Sagradas Escrituras, Cristo hizo de ella a lo largo de su existencia: "Le lit, c'est l'homme. Notre Seigneur Jésus, pour prouver qu'il n'avait rien d'humain, ne semble pas avoir jamais eu besoin d'un lit. Il est né sur la paille et mort sur la croix, laissant aux créatures comme nous leur couche de mollesse et de repos" (1969: 77). La cama marca el ciclo de vida de hombres y mujeres, seres perecederos en el transcurrir del tiempo, donde ese proceso de nacimiento y muerte se repite sisíficamente en una huera dinámica sin escapatoria. Sin embargo, asociado también a esa cosmogonía humana, en un principio bajo la idea de concepción, surge el sexo, cuya vertiente física atingente al placer es el centro sobre el que, en este caso en concreto, y confabulado con la libertad y el libre albedrío de los individuos que a él se abandonan, se construye el relato literario.

En los apartados que suceden a estas líneas introductorias veremos cómo la cama, más allá de su estrecha asociación con el deseo sexual $-\mathrm{y}$ por ende con el erotismo-, adquiría toda una variedad de significados que reafirmaban la lógica discursiva del texto. A este respecto Marcel Prévost deviene un referente al poderse constatar en su producción escrita el modo en que emplaza la imagen de la cama en los distintos episodios que expone en sus cuentos, piezas y novelas. Una representación cognitiva que permeabiliza en el discurso de la trama permitiendo al lector dotar de un significado preciso al mueble en cuestión según la escena que se describa.

\section{LA ERÓTICA DE LA CAMA EN LA LITERATURA PREVOSTIANA ${ }^{2}$}

La concepción que se posee de la cama como lugar de descanso, pero también como espacio físico donde se consume el acto sexual es común a todos los individuos. Una objetividad que se fundamenta en el carácter público que adquiere el objeto enunciado, y cuya representación cognitiva se genera a partir de la exteriorización lingüística del mismo. Así lo entendía el lógico alemán Gottlob Frege (1848-1925) al referirse a la universalidad que adquiría el concepto del objeto, aunque incidiera, a su vez, en el hecho de que los objetos y las funciones que se les atribuían eran mutuamente excluyentes (Valdivia, 2015; apud Blandin, 2002: 69). Al dotar a la cama de una funcionalidad concreta, o variada dependiendo de las circunstancias en la que se le dé uso, el objeto en sí transciende su razón de ser para convertirse en un instrumento narrativo más del escritor. La erótica de la cama adquiere entonces un protagonismo que no sólo se limita a la "actividad" que en ella se efectúa, sino que el propio enser se impregna de la

\footnotetext{
${ }^{2}$ Este apartado se esbozó en una conferencia impartida por el autor de este artículo el 31 de octubre de 2013, cuyo título fue el de "Del lecho conyugal al nido de amor: la cama como símbolo de pasión y erotismo en Marcel Prévost", dentro del II Coloquio Internacional de Género e Intertextualidad. Erotismo, sexo y otras prácticas literarias. Traducción y análisis desde una perspectiva comparada (francés-español)" celebrado en la Universidad Pablo de Olavide, de Sevilla.
} 
recreación del acto en sí tras la ausencia de los amantes. La visión de una cama con las sábanas arrugadas, los olores que de ella emanan o los objetos que a su alrededor se depositen, son igualmente representativos que las explícitas relaciones sexuales que en ésta se hayan podido realizar ${ }^{3}$. Ante la ausencia de los cuerpos, son aquellos elementos que evidencian la acción consumada los que dan testimonio de su ejecución, permitiendo recrear las escenas de la misma en la mente de quien los observa con detenimiento. De ahí que la sugerencia sea parte intrínseca del erotismo, idea que ya había sido expuesta por el escritor y antropólogo francés Georges Bataille (1897-1962) (1976: 151), cuando apuntaba que este fenómeno prevalecía incluso por encima de la resolución del acto sexual, encontrando éste en la literatura su "verdadera naturaleza" 4 . De este modo, y tras lo recién indicado, se deduce que basta con describir algunos planos de una cama para que el texto escrito nos permita evocar escenas que ya se han producido o imaginar otras que puedan tener lugar, dependiendo siempre del mensaje que de su narración se desprenda.

La obra literaria de Marcel Prévost, empero, no puede tildarse de erótica, ni tampoco existe entre sus obras una en concreto que pueda emplazarse de lleno en esta categoría, aunque sean múltiples los pasajes que encajen eventualmente en esta denominación. En la actividad escritural del novelista y dramaturgo parisino no se recurre a sugerentes descripciones (explícitas o metafóricas) que nos permitan entrever los detalles del acto sexual en sí o que pronostiquen o adelanten su realización; sino que, por regla general, se alude a éste como un pasaje de la trama que ya ha acontecido o que todavía está por venir sin incidir o recrearse demasiado en él. En su elenco narrativo, por consiguiente, no se encuentran obras como las de algunos de sus contemporáneos que sí han pasado a los anales de la literatura francesa como novelas de marcado erotismo ${ }^{5}$. Las piezas y novelas prevostianas no han sido nunca consideradas por la crítica literaria como eróticas, ni siquiera la más célebre de entre ellas, Les demi-vierges (1894), cargada de sugerentes insinuaciones que incluso le llevaron a ser denunciado por "desvelar los secretos de la

\footnotetext{
${ }^{3}$ Evidencia que se constata en toda manifestación literaria, especialmente en la poesía, siendo clara muestra de ello la célebre frase del poema "La mort des amants" de Les Fleurs du Mal (1857) de Charles Baudelaire (1821-1867), donde, con la promesa de un pronto estrépito pasional, se alude a los efluvios que de la cama emanarán cuando éste acaezca: "Nous aurons lits pleins d'odeurs légères" (2006: 472; citado por Robic, 2014: 136).

${ }^{4}$ En ese sentido, la literatura prevostiana, en lo que al erotismo respecta, puede ser considerada como una clara heredera de la novela libertina, dado que, en palabras de Jean-Marie Goulemot, ésta reposa sobre el arte de la seducción y del saber convencer con la insinuación al sujeto de deseo (Bokobza, 2000: 6).

${ }^{5}$ Algunas de estas obras son La Femme et le Pantin (1898), Les chansons de Bilitis: Pervigilium Mortis (1894) o Trois filles de leur mère (1926) —obra publicada a título póstumo- de Pierre Louÿs (1870-1925); Le Jardin des supplices (1899) o Le Journal d'une femme de chambre (1900) de Octave Mirbeau (18481917); Le Sûrmale (1902) de Alfred Jarry (1873-1907); Les onze mille verges ou les amours d'un hospodar (1907) o Les exploits d'un jeune Don Juan (1911) de Guillaume Apollinaire (1880-1918); Le Blé en herbe (1923) o L'ingénue libertine (1909) de Sidonie-Gabrielle Colette (1873-1954); Les caprices du sexe ou Les audaces érotiques de mademoiselle Louise de B. (1928) de Renée Duran (1892-1936); entre otras muchas de análoga índole.
} 
burguesía"6. Esto explica que el escritor y crítico dramatúrgico Jules Lemaître (18531914) tachara de "erótico cristiano" al escritor parisino, ubicándolo en un intersticio interpretativo entre el deseo y la razón (Bertaut, 1904: 29-30). Una atribución que no se alejaba en demasía de la realidad teniendo en cuenta que uno de los propósitos del autor era la conservación de los preceptos morales de la sociedad francesa, sobre todo aquellos que se esperaba de las damas y señoritas burguesas.

Con todo, los pasajes eróticos solían aparecer a menudo en el discurso prevostiano, siendo la cama el elemento alrededor del cual se generaba la acción. Escenas que se narran con detalle para estimular la imaginación independientemente de que se tratara de una cama con blancas y limpias sábanas de seda; una litera al uso improvisada en un gabinete de trabajo o en un recoveco oculto de la ciudad; un camastro sobre el que echarse por unos instantes; o incluso el lecho conyugal cuando la pasión remplazaba al hastío de la monotonía.

Una de estas estampas se reproducía en el ritual que acompañaba a las damas burguesas a la hora de desvestirse, acicalarse y meterse en la cama. En Cousine Laure este fenómeno de latente erotismo queda de manifiesto cuando Laure Castelain se desviste para introducirse en la cama con su madre, dado que ambas compartían el mismo lecho cada noche. Marcel Prévost (1906d: 34-35) detalla con sutileza cómo la joven artista se ponía el camisón mientras que dejaba al descubierto su vientre y ambos pechos, vistiéndose con una sonrisa provocadora, llena de confianza en sí misma y tras la atenta mirada de su madre que la esperaba entre almohadones (Imagen 1). En este pasaje, aún tratándose de un ritual habitual en la joven cantante de ópera y estando la madre siempre presente, el escritor parisino no disminuye ni un ápice la carga erótica, sino que la exacerba de forma intencionada. Laure, pese a ser una artista de mundo, sigue siendo virgen, y el hecho de que comparta la cama con su progenitora, incrementa esa sensación de desamparo e indefensión ante la brutal sensualidad masculina, lo que intensifica el erotismo del relato y hace mucho más ardiente el episodio en el que ella más tarde perderá su virginidad.

En Lettres de femmes puede hallarse un fragmento similar cuando Simone se desviste antes de acostarse con su marido. Marcel Prévost (1908b: 63-64) muestra una atractiva mujer de espaldas que deja al descubierto el reverso de su cuerpo, permitiendo imaginar los pechos desnudos al levantar ésta los brazos para deshacerse el moño. Un ritual donde la falsedad prevalece por encima de ese pretendido sacrosanto lugar de amor y confianza que debe ser el lecho conyugal, puesto que, momentos antes, en otra cama, Simone estaba abrazada a su amante, Ludovic, completamente desnuda. La dama burguesa se prepara para reposar su cuerpo exhausto tras la aventura que había tenido con su cómplice prometiéndose a sí misma, sin remordimiento alguno, volverlo a ver el jueves siguiente.

\footnotetext{
${ }^{6} \mathrm{Al}$ desvelar la existencia de las demi-vierges, Marcel Prévost daba a entender que las mujeres burguesas no eran los paradigmas conductuales que el discurso dominante esperaba que fueran, sino que, al margen de que pudieran permanecer vírgenes hasta llegar al matrimonio, en el sentido médico del término, eso no impedía que mantuvieran toda clase de relaciones sexuales que no pusieran en peligro la integridad de su himen (Luengo, 2016: 145-146).
} 
En la semi-virgen Maud de Rouvre, también vuelve a darse una situación análoga, pero no al meterse en la cama, sino al salir de ella. En esta ocasión, el escritor parisino reproduce la escena describiendo con todo detalle el cuerpo de la señorita parisina al quitarse sus atuendos de cama, tras haberse levantado y haber llamado a su doncella inglesa, Betty, para iniciar los protocolos de su aseo matutino y que le ayudara a vestirse:

Maud sauta en bas du lit, laissant aussitôt glisser de ses épaules sur le tapis, où vite l'Anglaise le ramassa, le souple tissu de linon. Tandis qu'on préparait le tub dans le cabinet de toilette, la jeune fille erra, tranquillement nue, de la commode où elle choisit elle-même les bas, la chemise, le pantalon qu'elle allait mettre, à la glace de la cheminée devant laquelle elle s'amusa à faire jouer dans ses boucles les reflets roussis du jour. Et cette blanche forme, de la nuque brune aux seins menus, aux hanches larges et pourtant tombantes, aux genoux étroits, aux pieds délicats, soignés comme des mains, toute cette blanche forme de Diane était si parfaite qu'elle restait chaste, de l'impudeur sacrée des marbres de déesse (Prévost, 1907b: 87-88).

Tanta era la perfección del cuerpo de Maud que su demiurgo literario la compara con una de esas estatuas clásicas de mármol, pero sin resistirse a la herejía de las formas, la aproxima más a lo divino que a lo humano, dado que comenta que la semi-virgen carecía de culpa al ofrecer una imagen de un ser casto y puro como la diosa Diana (Imagen 2). De hecho, así era, porque ésta permanecía virgen, pero bajo la noción de pureza y castidad que entendía el discurso patrimonial ${ }^{7}$.

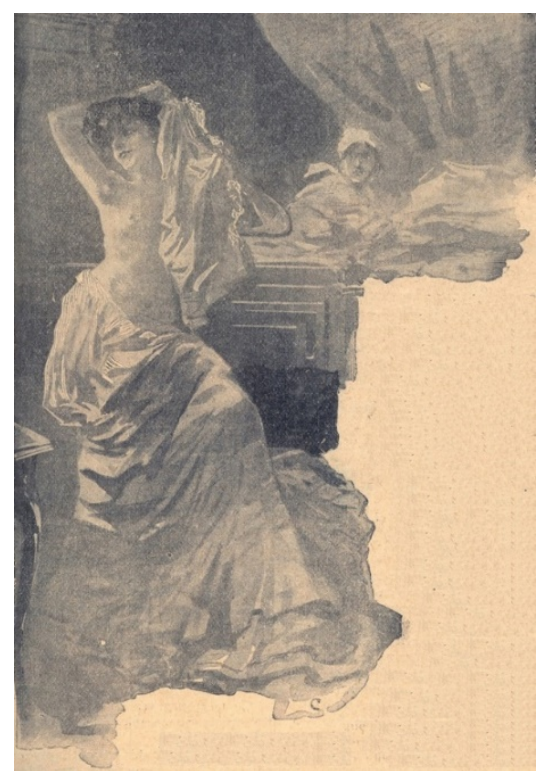

Imagen 1.

Acuarela de G. Conrad para

Cousine Laura. Mours du théâtre (1908).

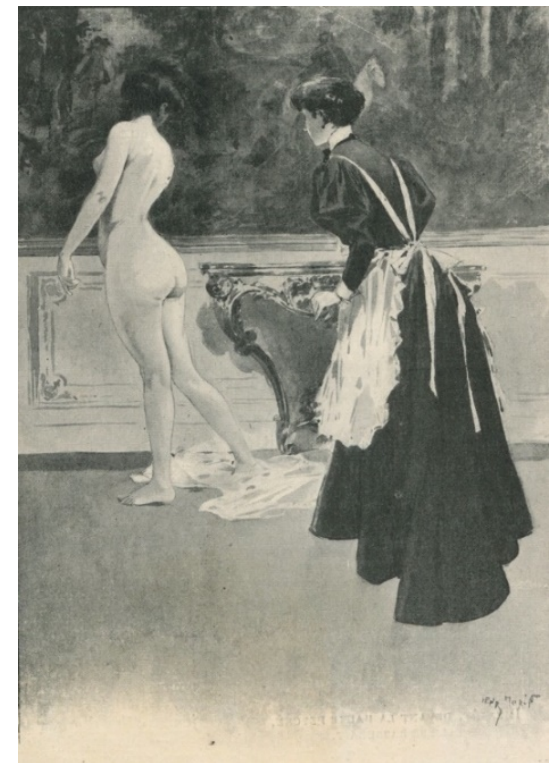

Imagen 2.

Acuarela de H. Morin para Les demi-vierges (1907).

\footnotetext{
${ }^{7}$ En este discurso, según la obra de Alain Corbin (1998), las mujeres eran concebidas como propiedad privada, sobre todo bajo la concepción burguesa de la vida, la cual venía apoyada por la Iglesia, enclave moral, pero también político y económico, a partir del cual se mantenía el orden social.
} 
Conforme a lo recién expuesto, y a lo apuntado con anterioridad, Adolphe Brisson (1860-1925), en la biografía que publicaba Jules Bertaut sobre Prévost, ensalzaba esta significativa particularidad del escritor parisino del siguiente modo: "Il a pour lui un talent clair, une forme aisée, une imagination séduisante ; il sait unir la logique au romanesque ; il possède l'art de plaire aux femmes en leur posant des problèmes qui émoustillent leur curiosité" (Bertaut, 1904: 29; apud Rochefort, 2003: 353). Más allá de su proyecto de regenerar a la sociedad francesa a través de la instrucción de las jóvenes — siendo un claro ejemplo de ello su trilogía de Lettres à Françoise- Marcel Prévost buscaba también captar la atención de las mujeres burguesas narrando los entresijos de su actividad relacional en los círculos sociales en los que interaccionaban. La trilogía de Lettres à Françoise (Lettres à Françoise, Lettres à Françoise mariée y Lettres à Françoise maman) estaba dirigida a una mujer nacida en una familia burguesa, cuyo estatus mantenía desde lustros, donde su "ternura misteriosa" de dama decimonónica se complementaba con su recién adquirido gusto por lo moderno y su admiración por los avances técnicos e ideológicos de la época (Prévost, 1908a: 12; apud Angenot, 1983: 336; Petcoff, 1992: 1). Este compendio escrito en forma de manual, al igual que gran parte de la producción novelística prevostiana, se focalizaba en todas aquellas mujeres que estaban interesadas en saber cómo estar en sintonía con el nuevo siglo que pronto iban a empezar, con el objeto de ser, en cierto modo, abanderadas de una Exposición Universal de 1900 que traería consigo nuevas libertades para todo su sexo.

Si existe un erotismo en Marcel Prévost, como apunta José Ignacio Velázquez (2004: 223), éste no es fisiológico, sino psicológico ${ }^{8}$, en tanto que el autor busca atrapar al lectorvoyeur - sobre todo al femenino - valiéndose de un texto en el que él mismo introduce las imágenes que le exige su deseo. Acción que, no obstante, también se desarrolla en función de las normas que impone su juicio y voluntad, donde la cama, como elemento constituyente, puede devenir el eje sobre el que se construye la trama del relato.

\section{LA SACRALIDAD DEL LECHO CONYUGAL}

\subsection{La permeabilización del sexo en lo sagrado}

Las implicaciones simbólicas que trae consigo el lecho conyugal van más allá de la concepción de lugar común de descanso y de confidencias, puesto que es en su seno donde también se consume y afianza el matrimonio por la proximidad, el conocimiento y la interacción de los cuerpos de sus integrantes y la complicidad de los espíritus. De igual modo, bajo la óptima masculina del escritor parisino, en esa misma cama es donde, en

\footnotetext{
${ }^{8}$ En Le jardin secret, Marcel Prévost asocia el amor-espiritual con la posesión física del cuerpo, sin hacer mención, no obstante, a los placeres que aportan uno y otro. Más tarde, indicará que sólo cuando el amorespiritual se hubiera asentado en un mismo y único latir, llegaría la excitación del gozo físico del cuerpo, por lo que pedía a sus lectoras que tuvieran paciencia (Prévost, 1906a: 63; apud Petcoff, 1992: 178).
} 
teoría, muchas señoritas burguesas perdían su inocencia y virginidad al iniciarse en el terreno del sexo, por lo que la cama se convertía en testigo de ese momento clave grabado por siempre en su memoria. Todo un cúmulo de recuerdos asociados a ese "nido de amor" que irán acumulándose con el tiempo y de los que, según el discurso patrimonial, difícilmente una mujer podrá evadirse si en alguna ocasión decide divorciarse, separarse u optar por el ostracismo de la voluntad del marido. Catherine Clément reafirma esta evidencia al señalar que la sociedad se rige según el principio "masculino puro", mientras que lo sagrado reside en el principio "femenino puro" (Clément, Kristeva, 2000: 72). A tenor de esta apreciación, donde todo lo considerado femenino es susceptible de ser asociado con lo sagrado —entiéndase "femenino" el sentido más estricto del término ("puro")—, el lecho conyugal pasaba a ser parte constituyente de la identidad femenina como extrapolación de la misma sobre el objeto físico de la cama.

Esa veneración por el mueble en sí puede constatarse en L'heureux ménage, donde Cécile Royaumont, antes de irse al Flandes francés y abandonar a su marido por sus infidelidades, pernota cómo se siente atraída por la cama vacía como si de una fuerza sobrenatural se tratase: "le grand lit désert, qui fut notre lit, attire mes yeux malgré moi vers le fond demi-obscur, par la blancheur magnétique des oreillers, des draps entr'ouverts" (Prévost, 1907a: 97). En ese instante, asaltan su mente todos aquellos momentos pasados junto a su marido, destacando, entre todos esos recuerdos íntimos ${ }^{9}$, el nacimiento de su hija Geneviève, pero también todas aquellas lágrimas que había vertido por sus infidelidades. Ese cúmulo de pensamientos le impedía que pudiera arrodillarse para rezar con el fin de hallar la paz interior y poder así afrontar la noche, y encontrar el descanso de su cuerpo y alma. En este sentido, como el mismo Prévost ya había apuntado en Mademoiselle Jaufre, la cama en el matrimonio, adquiría las mismas funciones que un verdadero altar ${ }^{10}$ :

Je constate que mes tristesses ne touchent pas la Providence. Alors, impuissante à prier, je pleure. Mes lèvres se collent doucement à ce lit qui a été notre lit, où mon mari a dormi près de moi, où Geneviève fut conçue. Quand je serai là-bas, dans les Flandres, je prierai tante Émilie d'écrire à Paul, pour qu'il me donne ce lit... je ne veux pas qu'il soit profané (Prévost, 1907a: 101).

Esos minutos de oración, sobre un altar que probablemente pronto sería mancillado por su marido y su respectiva amante, quedaban interrumpidos por los miedos que asaltaban a la dama burguesa ante la posibilidad de verlo desaparecer y, con él, toda su memoria de vida familiar. La cama se convertía aquí en una prolongación de su propio

\footnotetext{
${ }^{9}$ Uno de esos momentos fue la luna de miel de Cécile Royaumont con su marido, Paul, la cual duró dieciocho meses y en la que se instalaron en el Royal Hotel de Devonshire, en Teddington (Inglaterra), donde tenían por costumbre sentarse en un banco para besarse bajo la luz de la luna mientras escuchaban cómo las olas del mar rompían contra las rocas (Prévost, 1907a: 18).

${ }^{10}$ Esta alusión al carácter sacramental de la cama puede leerse en el pasaje donde Mme Hoc, hablando a su hija Marthe y a Camille Jaufre sobre el matrimonio, menciona el libro de los Salmos y del Cantar de los cantares para aludir al lecho conyugal como un verdadero altar (Prévost, 1907c: 39).
} 
ser que merecía respetarse de igual modo que su persona, por lo que poco ha de extrañarnos que Mme Royaumont decidiera llevársela con ella a Lille (Imagen 3).

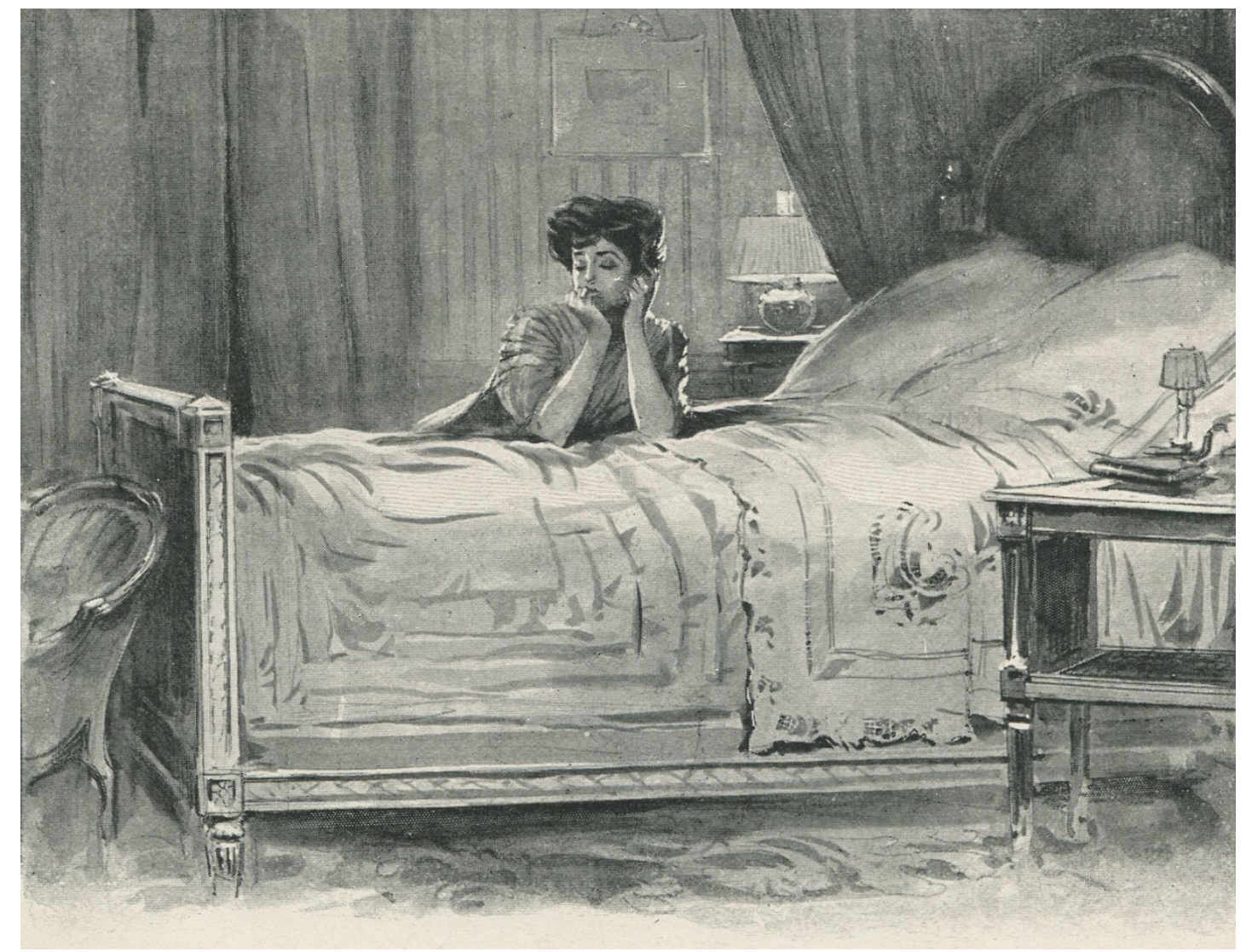

Imagen 3.

Acuarela de Lapierre para L'heureux ménage (1907).

Esa costumbre de tomar la cama como altar, no obstante, en la obra de Marcel Prévost también se entremezcla con lo erótico, ya que son muchas las plegarias hechas en su seno que tienen un marcado componente - directo o indirecto - sexual. Así, en L'automne d'une femme, Julie Surgère reza a Dios con el fin de que le dé fuerzas para resistirse a los encantos del joven Maurice Artoy del que se encuentra enamorada, sobre todo al presentarse éste como una latente tentación al residir en su propia casa y dormir a pocos metros de ella y su esposo (Prévost, 1906b: 15). Una letanía de plegarias nocturnas con las que la mujer buscaba anestesiar el febril deseo que activaba la erótica de su imaginación. Algo parecido pasaba con Mme Aubry, quien procedía de análogo modo cuando, en el cuento "Le meurtre de Madame Aubry", hacía sus oraciones cada noche antes de irse a dormir. Un ritual al que tenía acostumbrado a su marido, viéndola éste como un admirable ejemplo de devoción y castidad. Esto explica por qué la noche en que su mujer no procedió como era de esperar, al encontrarse agotada por el trasiego diario, su marido la asesina al creer que ese cansancio se debía a que había estado practicando sexo con otro hombre durante todo el día (Prévost, 1911b: 82). En ambos casos, la 
banalidad de las oraciones se entremezcla con lo sagrado del rito en sí, aunque, a pesar de ello, sigue existiendo ese vínculo con lo divino y el respeto por los dictámenes de la moral cristiana al invocar al Altísimo.

Este respeto por el ente divino, sin embargo, se ve distorsionado cuando se hace objeto de culto a la persona que reposa encima del lecho o, más en concreto, con la que se ha mantenido relaciones sexuales. Julien de Suberceaux, el "desflorador" profesional de Les demi-vierges, es un ejemplo representativo de este fenómeno, al no querer deshacer la cama y acostarse en ella, pues todavía perduraba el olor del cuerpo de Maud de Rouvre sobre el cubre-pies que parcialmente la tapaba. Con frases entrecortadas, el eventual amante se lo confesaba a la semi-virgen, recordando incluso en su confesión la fecha exacta del día en que todo ocurrió:

— La dernière fois surtout... la dernière fois que tu es venue... le 3 janvier... Oh ! que tu es belle. Maud... il n'y a rien de pareil à toi... Il était resté l'odeur de tes cheveux, de tes bras, sur le couvre-pied du lit fermé... Je n'ai pas voulu qu'on ouvrît ce lit et je ne m'y suis pas couché, jusqu'à ce que cette odeur fût toute partie... Et tu ne veux plus ! (Prévost, 1907b: 12).

Esa ausencia aludida por Suberceaux se manifiesta de otro modo en Mademoiselle Jaufre, donde la sacralidad de la cama queda reemplazada por el silencio y el secreto de una confesión ahogada. Este hecho se debe a que Camille nunca mencionará a nadie las visitas nocturnas del capitán corso Jérôme Giacometti a su habitación para mantener relaciones sexuales con ella. Un acto que se repetirá durante varias noches, entrando y saliendo el oficial por la ventana, y siendo la resistencia de la joven cada vez menos firme, bien por los placenteros beneficios que le reportaba estos encuentros sexuales o porque, tras ser mancillado su cuerpo, ya no había mucho que preservar y prefería dejarse llevar por la complacencia carnal del sexo furtivo (Prévost, 1907c: 51-52). Con todo, durante las horas diurnas, el recuerdo de la cama y del sexo en ella consumado, acrecentarán el anhelo y el deseo de su continuidad en la mente de la joven franco-italiana. Esa lascivia sin palabras dará paso a un profundo sentimiento de culpa que aflorará también en la cama cuando duerma al lado de su marido, Louis Lhotte, estando embarazada de su antiguo amante furtivo.

Aunque el episodio recién narrado no se produce en el lecho conyugal, sino en el de una joven burguesa que descubre por primera vez el sexo, el reposo en ese templo de paz, según apunta Marcel Prévost, no sólo se consigue con la convivencia, la confianza y la complicidad existente entre los cónyuges, sino también - y sobre todo- gracias a la fatiga de los cuerpos por el acto sexual. Así lo manifestaría Mme Duclozac en Nouvelles Lettres de Femmes, en la segunda parte del cuento que el escritor parisino dedica a la cama en sí, "La Question du lit II", donde insistía en que el único y verdadero descanso se alcanzaba después del sexo: "Le lit unique, où l'on est deux, est instrument d'amour, point autre chose. S'il est permis d'y dormir, c'est que la plus généreuse ardeur des amants est bornée par la défaillance des corps ; mais il faut dormir encore enlacés, lèvre contre 
lèvre, les membres rompus et les yeux meurtris" (Prévost, 1908b: 44). Ese descanso "sin previa actividad" aparece aquí como algo que está permitido, pero no era la auténtica funcionalidad para la que la cama había sido concebida. Esta idea ya se había repetido antes en la novela titulada Cousine Laure, donde Henri Nodier, tras haber mantenido relaciones sexuales con Laure Castelain, cae rendido en su cama durmiendo plácidamente: "Il dormit d'un sommeil appesanti, opaque, que nulle transparence ne traversa. Il dormit écrasé par cette paix de la chair qui, dans la jeunesse, venge et restaure toutes les fatigues, affirme la victoire définitive de la nature bienfaisante sur les dévergondages de la volonté" (Prévost, 1906d: 120). El cansancio del acto sexual intenso, como demuestra la literatura prevostiana, movido por la pasión del deseo, genera en el cuerpo y el espíritu la paz necesaria para lograr el idóneo descanso que restablezca los sentidos, pero nunca es lo mismo para una pareja de amantes que para un matrimonio consolidado.

\subsection{Un sommeil à deux con el marido o el amante}

Dormir al lado del marido o de "el otro" era un acto muy dispar, porque, si uno traía la paz de espíritu, el otro facilitaba la consecución de la del cuerpo. A tenor de lo apuntado por el escritor parisino, y aunque ambos reposos parecen ser iguales de satisfactorios, el sereno equilibrio que supuestamente aportaba el sueño de un matrimonio, constante y uniforme, contrastaba con el provocado por la convulsa pasión quemada en un acto sexual adúltero, cuyo descanso era mucho más profundo y físico que el anterior. Así lo contaba la viuda Duchâtelier a Mme d'Oissy, en Lettres de femmes, en una carta que escribía sobre esta comparativa una vez que ya se había quedado viuda y podía confesar que durante el tiempo en que estuvo casada también vivió una aventura con otro hombre:

Oh! cette question du lit pour deux, où l'autre vient à manquer, c'est toute la psychologie des veuves, vois-tu! Certes, mon mari n'excitait pas outre mesure ma sensibilité, et le devoir conjugal, qu'il avait la discrétion d'exiger rarement, n'a jamais cessé d'être un devoir pour moi. Mais n'importe: il était là; je me réchauffais à la chaleur de son corps de brave homme; j'avais conscience d'une tendresse, d'une protection toutes proches de moi; les quelques paroles que nous échangions le soir et le matin résumaient ou préparaient la journée dans un affectueux recueillement... Quand il n'a plus été là, le pauvre ami, j'ai souffert de mon isolement comme je souffrirais du froid, si, l'hiver, on m'ôtait mon édredon : une vraie peine physique se mêlait à mon chagrin de cœur. Puis, quand je suis devenue la maîtresse de Frédéric, l'agitation nerveuse de cette reprise d'amour m'a valu de longues insomnies où je pensais: "S'il était là, pourtant, près de moi, contre mon cœur, le cher aimé! Quelle douceur de dormir entre ses bras, de prolonger le baiser du soir jusqu'au baiser du matin!'. Il me semblait que le sommeil à deux, avec lui, serait une caresse nouvelle, ignorée, la seule qu'il ne m'eût pas donnée encore (Prévost, 1906c: 112).

En ese conflicto de la "cama para dos" (lit pour deux), la sacralidad que le otorgaba Marcel Prévost únicamente cristalizaba en el seno del amor conyugal, es decir, en el 
matrimonio. Si bien la actividad que pudiera darse en la cama era mucho más física y carnal cuando se trataba de dos amantes, la comunión de espíritu entre los cónyuges en el tálamo nunca cristalizaría de igual modo a la del acto adúltero. En lo sagrado, el amor es un sentimiento que exige un mínimo de libertad y reciprocidad entre aquellas personas que se encuentran enamoradas, pero en el amor pasional no existe esa democratización de los sentimientos (Clément, Kristeva, 2000: 164). Esto explica que Marcel Prévost, en L'heureux ménage, acuñara el término de "sueño a la par" (sommeil à deux) para referirse al reposo conjunto entre marido y mujer. Una democracia de sentimientos cuya "sacralidad", en verdad, únicamente cristalizaba durante las inconscientes horas de sueño que el matrimonio consumía sobre el tálamo conyugal, cuando los rumores de infidelidades —o la fatal acción consumada-, tras las lágrimas volcadas sobre la almohada, se diluía en el sosiego del perdón y de la aceptación (Imágenes 4 y 5). En esta ocasión, Cécile Royaumont, tras reconciliarse con su esposo, Paul, comenta las sensaciones que experimenta de nuevo al dormir en la misma cama con él, un bienestar que hace que olvide el motivo del porqué se separó:

Une crise irréfléchie de sensibilité nous sauva, nous remit dans l'ordre — car c'est l'ordre, à mon avis d'âme conjugale - le mari victorieux, satisfait de lui-même, l'épouse vaincue et reconnaissante... Après, il advint cette chose salutaire: Paul dormit sur mon cœur, et moi je dormis avec cette tête adorée posée contre moi, enlacée par mon bras. Dans le sommeil ainsi confondu de deux êtres qui se sont une fois aimés, s'élabore la reprise de l'amour. Nos forces instinctives de tendresse travaillent merveilleusement, à notre insu, pour nous joindre encore pendant la coule, autour de notre repos, le sable furtif des heures nocturnes... Sommeil à deux! Repos meilleur, plus actif que la vie!... Les cœurs désunis s'y refondent, s'y recollent, comme les lèvres d'une plaie lorsque dort le blessé (Prévost, 1907a: 110).
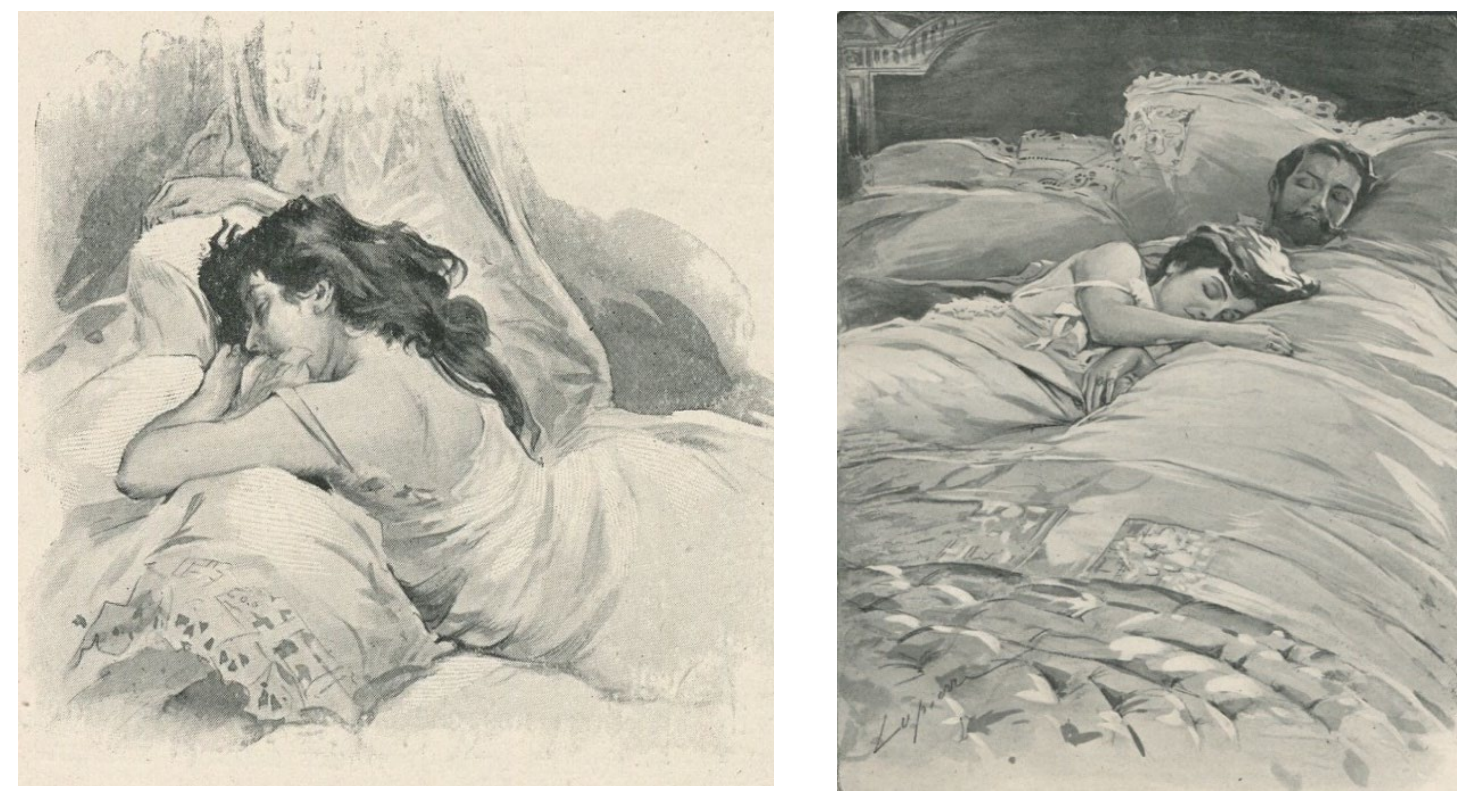

Imágenes 4 y 5 .

Acuarelas de Lapierre para L'heureux ménage (1907). 
En la literatura prevostiana, la sacralidad atribuida al lecho conyugal sólo puede ser concedida por parte de las mujeres, al igual que únicamente éstas son capaces de advertir la diferencia que existe entre dormir con el marido o con el amante. Todo lo que contraviene al "orden lógico" y quebranta aquello que los dictámenes del sistema de poder vigente predispone para el fuero interno de los individuos en función de una canonizada entelequia de bondad, todo ello, se aleja de lo femenino (Clément, Kristeva, 2000: 126). De ahí que Cécile Royaumont se describa como "alma conyugal”, fiel a los preceptos marcados por el discurso dominante, que acepta con resignación los devaneos de su marido con Ida Fürst, cumpliendo así con el modelo de sufriente vestal de la feminidad tradicional. El lecho conyugal se convierte en un ensalmo que todo lo cura, que recarga el amor perdido con nuevas ilusiones y promesas de un futuro mejor. Acción que opera entre sábanas, y que se manifiesta como un "sueño a la par", aunque el "universo onírico" donde se hunden los cónyuges esté constelado de hueras parcelas patrimoniales.

\section{LA SUBREPTIVA AMATORIA DE LA CAMA}

\subsection{Camas clandestinas para amantes diurnos}

Marcela Lagarde (2002) comentaba que existía una amplia variedad de amantes: diurnos, nocturnos, casuales, eventuales, ocasionales, aventurados, arriesgados, etc., cuya categorización dependía de las circunstancias en las que sus encuentros erótico-amorosos acaecían y la identidad de cada uno de sus protagonistas ${ }^{11}$. De entre todos ellos, destacaba la figura de aquel clasificado como "diurno". Un hombre que por la noche volvía junto a su esposa, puesto que únicamente se ausentaba de su lado para pasar un breve espacio de tiempo con su amante durante el día. Unas horas reservadas para el sexo y el breve descanso del cuerpo exhausto que pudiera resultar de esta actividad extramatrimonial. Amantes que no experimentaban ninguna ilusión por el encuentro furtivo, ni tampoco sentimiento de culpa por la infidelidad y la traición consumada, sino sólo se movían por el impulso de satisfacer las exigencias de su lascivia.

Un sentimiento que Simone, la autora de las páginas de un diario que reproduce Marcel Prévost (1906c: 61) en Lettres de femmes, confesaba sentir cuando se dirigía a la avenida Montaigne para reunirse con Ludovic en el espacio que éste había acondicionado para sus encuentros amorosos. El lugar en sí que no tenía glamur alguno, no era más que una habitación alejada del trasiego cotidiano de la gran ciudad, con una cama sencilla, acorde con ese espacio clandestino, pero que, como un imán, atraía con fuerza a la dama burguesa. El escritor parisino demuestra aquí que las mujeres también podían ser "amantes diurnos", transgredir las normas establecidas para su condición social e

\footnotetext{
11 Anotación tomada en el Congreso Interdisciplinar sobre Educación y Género organizado por la Asociación de Estudios Históricos de la Mujer de la Universidad de Málaga y celebrado los días 20, 21 y 22 de marzo de 2002.
} 
identitaria, profanar "lo sagrado" y, en definitiva, tener "derecho al mal" 12 . Una libertad de conducta análoga a la de sus congéneres masculinos y, por ende, inherente a su condición. Simone era una "amante diurna" que se escapaba durante las horas de luz para acostarse con otro hombre que no era su marido, como supuestamente también lo había sido Mme Aubry (Prévost, 1911b: 79-83), volviendo a casa con su esposo, Jean, cuando todavía el sol estaba en lo alto, aunque en este último caso no fuera más que una suposición.

En la literatura prevostiana, en concomitancia con el proceder recién descrito, se observa cómo de esa "cama al uso", aquella que no servía más que para tener relaciones sexuales ocasionales —instrumento impersonal, pero de erótica sugerente-, se desprende esta tipología de amante. Una clara muestra de ello se da en Nouvelles lettres de femmes con M. Duclozac y M. Anquetin, en concreto cuando la mujer del primero de ellos, en una carta dirigida a la del segundo, Mme Anquetin, pensando en su propia situación, apuntaba que el esposo que se resigna a dormir en una cama distinta a la de su mujer es porque hace la siesta en compañía de otra:

Chère, je ne m'en suis jamais préoccupée, et je conviens volontiers que j'eus tort. J'aurais dû réfléchir que les hommes sont autrement fabriqués que nous; qu'ils prennent un vif plaisir à ce qui nous procure seulement un peu d'énervement; que l'époux si aisément résigné à coucher seul, la nuit, fait peut-être... sa sieste, en plein jour, ailleurs que chez lui (Prévost, 1908b: 41).

Resulta curioso que Mme Duclozac apunte que las mujeres están "hechas de otra pasta", porque, en realidad, como el escritor parisino demuestra a lo largo de toda su producción literaria, las mujeres burguesas procedían del mismo modo que los hombres, siendo, además, con su refractaria actitud, incluso mucho más transgresoras que ellos. Mme Anquetin, a su vez, respondía a su interlocutora señalando que durante seis meses había "disfrutado" cada noche de lo que podía darse en llamar un "marido constitucional", uno de esos que se acostaban en la cama sin después cansarse, cuando de él se esperaba precisamente todo lo contrario (Prévost, 1908b: 46). Este comportamiento contradecía las consensuadas exigencias conductuales que, en teoría, implicaba el hecho de meterse en la cama "en compañía", acción en la que el sexo cobraba un papel predominante por encima incluso del dormir.

Al igual que Ludovic, el amante de Simone, otros muchos caballeros también tenían un espacio donde reunirse con sus amantes, como era el caso de Jean Lecoudrier, en Le jardin secret, cuyo apartamento situado en la parisina calle Lafayette estaba acondicionado para recibirlas. Marthe Lecoudrier descubre ese lugar y, al entrar en su interior, allí emplazada, verá la cama donde su marido acogía a aquellas mujeres con las que calmaba sus pulsiones sexuales. Con un sentimiento mezcla de tristeza e ira, la esposa engañada contemplará ese mueble diseñado para el placer encubierto, huyendo entonces

12 Amelia Varcárcel (2020: 169) apunta que ese "derecho al mal", sin embargo, las mujeres no lo reivindican, sino que lo ponen por obra con los riesgos que asumen por ello. 
lejos al no poder mantener su mirada sobre él por más tiempo (Prévost, 1906a: 106). Todavía más clandestino era el lugar del que Julien Corambert, el amante de Mme Dutheil en Dernières lettres de femmes, disponía para reunirse con sus conquistas amorosas. Al parecer, en la calle Nollet, donde habían tres viejos anticuarios, en la trastienda de uno de estos comercios, se escondía una habitación destinada a veladas íntimas donde el sexo era el protagonista. En la carta que Mme Dutheil escribe a Mme de Trans, ésta cuenta cómo, anticipándose a la cita que su amante le había dado para reunirse con él, llega a ese lugar $y$, viendo la cama donde pronto estaría echada junto a él, piensa en todas las mujeres que por ahí habían pasado:

Et soudain j'évoquais toutes les femmes qui déjà s'étaient glissées dans ces draps-là, et qui avaient donné leur corps à Julien... Combien de femmes? et quelles femmes? Des filles; des petites bourgeoises "levées" au hasard d'une flânerie (il m'a raconté quelques histoires de ce genre)... des femmes du monde, aussi... [...] Toutes, elles étaient montées sur ce chevalet d'amour, pour de l'argent ou pour du plaisir, afin de procurer une secousse agréable au jeune Julien Corambert, attaché aux Affaires étrangères (Prévost, 1909: 117).

En esta evocación a todas aquellas mujeres que en esa cama habían mantenido relaciones sexuales con Julien Corambert, Mme Dutheil comprende que no desea ser una más, porque, aunque su anhelo era el de acostarse con el joven diplomático, si así procediera correría el riesgo de "quemarse moralmente" sin poder nunca volver atrás (Prévost, 1909: 117). Con todo, más allá del "noble" acto de la dama burguesa, el hecho que realmente la disuade de cometer la infidelidad es el que esa cama carecía de un mínimo de "sacralidad". Mme Dutheil buscaba un "sueño a dos" que, si bien no poseería las atribuciones espirituales que se le concedían en el matrimonio, al menos no se viera privado de esa dualidad que hiciera de su relación adúltera algo único.

De forma más cómoda se había organizado Paul Royaumont en L'heureux ménage, pues instala una sala de estar en el mismo despacho, en la que, con sólo apretar un botón eléctrico, aparecía un lavabo y una cama al uso. Se trataba de un den inglés que había visto en la tienda de un tapicero de Tottenham-Court-Road, en Londres, durante su luna de miel, rumiando ya en aquel entonces que compraría el mueble nada más volver a París (Prévost, 1907a: 18-23). Esto nos lleva a pensar que ya tenía previsto el uso que a él iba a darle. A esa misma salita acudirá Ida Fürst, con quien el caballero pretende tener relaciones sexuales, pero no consigue convencerla para que acceda a su solicitud (Prévost, 1907a: 47). Obviamente, a su esposa, Cécile Royaumont, la presencia de este den en el lugar de trabajo de su marido no le agrada en modo alguno, puesto que lo considera algo poco profesional, además de una evidente falta de respeto hacia su persona. Lo más sorprendente es que cuando la dama visita a M. Lebrazier, el abogado que va a llevarle los papeles del divorcio, constata que, en su despacho, éste también tiene el mismo den ${ }^{13}$

\footnotetext{
${ }^{13}$ En los despachos, no obstante, lo habitual era mantener relaciones en los divanes, mueble que, por otra parte, también podía encontrarse en otros contextos, como restaurantes, cabarés, pisos acondicionados para ocasionales encuentros de índole sexual, etc. Así, Julie Surgère y Maurice Artoy, en L'automne d'une
} 
(Prévost, 1907a: 87). Esto demuestra cómo la moralidad de los hombres burgueses de la época prevostiana, más allá de la considerada como "doble moral", en realidad, era tan variable como tipos de cama había y las circunstancias que las acompañaban.

\subsection{Lechos sin reposo}

Existen otras camas donde la actividad nunca cesa, donde el silencio y la quietud raramente se dan, y donde el reposo se metamorfosea, contra toda lógica, en un cansancio de cuerpo sobrevenido por las imposiciones del placer, la consumación del deseo y de la lascivia desbocada de los amantes. En la obra prevostiana, la variedad más común de esos "lechos sin reposo" era la cama de prostitutas, meretrices y eventuales mesalinas ${ }^{14}$. Algunos de los relatos que atestiguan esta evidencia son el cuento "Zabeau", donde una artista de cabaret llamada Isabelle de Navarin, conocida en la intimidad de los camerinos como Zabeau, recibía a sus clientes en una misma cama donde realizaba el servicio por el que se le pagaba, mientras que, a pocos metros de ella, en la habitación contigua, dormía su hija pequeña, una niña de ocho años que estaba siempre a su lado (Prévost, 1911a: 95); la novela Cousine Laura, en la que aparece una prostituta italiana, echada desnuda sobre un camastro con una insinuante postura de esfinge, que Henri Nodier encuentra en un elegante prostíbulo de Nápoles (Prévost, 1906d: 56); o, en La paille dans l'acier, donde una belle de jour intersecular, Mlle Charlotte Prins, haciéndose pasar por una condesa española que estaba de paso por París, se prostituye por placer, sin que sepa nada su marido, Robert Ponceteau, y que el amigo de éste, Louis Delzanne, encuentra muy ligera de ropa sobre una cama en una clandestina casa de citas (Prévost, s.a.: 69). En todos estos casos, y otros igual de representativos, la cama se convierte en un mero "instrumento de trabajo", sin poderse asociar a la identidad de quien la utiliza con ese fin. Su reiterado uso con tantos hombres distintos diluye el vínculo que se establece entre su propietaria y el mueble en sí, ya que el descanso y el sueño en su seno son meramente eventuales. La constante dinámica de acción, que en materia de sexo en él se produce, destruye cualquier

\footnotetext{
femme, solían hacer el amor en el diván del apartamento que el joven tenía en la calle Chambiges (Prévost, 1906b: 124). De igual modo, en el del reservado de un cabaré, de nuevo sobre un diván, la condesa desconocida protagonista de la historia "Au cabaret", recogida en Lettres de femmes, empieza a desnudar y a "manosear" el cuerpo de la joven Mlle Cécile Lhéritier (Prévost, 1906c: 16). En este último caso el autor alude a la homoerótica femenina, que, en la obra prevostiana, suele aparecer de forma intermitente, siendo el más claro ejemplo de ello Chonchette. Aparte de los divanes, también los sofás eran eróticos recursos alternativos a la cama, y no sólo en el periodo intersecular aquí abordado, sino ya en el siglo XVIII, como lo demuestra el cuento "Le Sopha, conte moral" (1740) de Crébillon fils (1707-1777), donde su protagonista, Amanzéí, se transforma en sofá relatando todo lo que sobre él ocurría, especialmente en materia erótico-amorosa (Vázquez, 1996: 79-80).

${ }^{14}$ Resulta innegable que Marcel Prévost conocía muy bien al colectivo femenino, sobre todo a aquellas "mujeres de mundo" (femmes du monde) con las que trataba en las vespertinas y nocturnas veladas de sociedad, pero a diferencia de éste, que se consagraba casi en exclusividad al público femenino, en la literatura de los libertinos, escrita mayoritariamente por hombres, su destinatario era el masculino (Vázquez, 2004: 78).
} 
intento de asociarlo a la concepción y al significado que de la cama como lugar de reposo suele atribuirse.

Los hombres, no obstante, también darán ese particular uso a la cama, recibiendo y despidiendo a damas y señoritas a diario, produciéndose incluso la situación de que alguna de ellas perciba la presencia del cuerpo de la precedente o intuya el de la venidera. Así, en Lettres de femmes, Simone visita por sorpresa a su amante, Ludovic, encontrándolo todavía durmiendo a las once de la mañana - supuestamente al haber estado con otra mujer durante toda la noche- - y algo impaciente al estar pendiente del reloj por una supuesta pronta visita. La esposa infiel le comunica que está embarazada, pero no sabe si es de él o de su marido, dado que también había mantenido relaciones sexuales con este último, cuando ambos amantes habían acordado que se serían fieles el uno al otro (Prévost, 1906c: 65-66). A diferencia de la cama de las prostitutas, en la del amante que recibe a mujeres en su lecho para tener sexo, supuestamente todas ellas infieles a sus esposos, en esta ocasión no deja de estar en ningún momento vinculado al uso del propietario, convirtiéndose en parte integrante de la identidad del mismo, ya que en él también puede encontrar el sosiego y reposo que a la cama se le concede.

\section{LA CAMA PROPIA COMO METÁFORA DE LIBERTAD FEMENINA}

La cama podía ser concebida como metáfora de la libertad femenina, siempre y cuando este mueble fuera de uso exclusivo de una mujer, y los sueños que en él se generaran fueran inducidos por su propia voluntad creadora. Nada que ver con el lecho conyugal donde el mundo onírico de aquellas damas burguesas interseculares se conformaba a la par con el que imaginaba su esposo. Una cosmogonía mixta que se establecía a partir de un contrato patrimonial validado por un intransigente discurso moral, legal y religioso. La intimidad que estas mujeres experimentaban al tener una cama para sí solas, sobre todo tras haberse casado, era inherente a una ontogenia psicológica en la que iniciaba esa toma de conciencia de ser sujeto libre y de pleno derecho. En ese espacio rectangular, entre sábanas sin improntas ajenas, cualquier mujer podía soñar despierta en mejores condiciones de vida para ella y sus congéneres de sexo. De ahí que la cama adquiriera un significado cuyo enfoque interpretativo podía ser incluso concebido como una extrapolación de la identidad femenina. Ser libre equivalía, por lo tanto, a tener una cama para una sola, donde el descanso, el sexo y el amor serían elección de toda mujer. Así lo manifestaba Étiennette Duroy a Maud de Rouvre, cuando, en Les demivierges, le exponía sus deseos de independencia, los cuales empezaban por poder disfrutar de una cama que le fuera propia y de la habitación donde el mueble en cuestión se ubicara: "je veux essayer de vivre indépendante, d'avoir ma chambre et mon lit bien à moi, de me suffire" (Prévost, 1907b: 16). El propósito de la señorita burguesa era el vivir de modo independiente, sin estar supeditada a nadie, y disfrutando de un espacio nocturno que le fuera propio con su particular cama al uso. 
Este deseo significaba que poder comprarse una cama pasaba por la consecución de la emancipación económica y del ser capaz de valerse de sí misma para salir adelante. En ese sentido, la paulatina incursión del colectivo femenino en el ámbito laboral posibilitó el acceso a este privilegio que no todas las mujeres podían permitirse. Disponer de una cama para una misma, suponía dejar de estar sujeta a los deseos del marido, ser un complemento más a la actividad profesional y vivencial del cónyuge, y de concebir el lecho conyugal como un enser con meros fines reproductivos. En este último aspecto, en Le jardin secret, Marthe Lecoudrier lo entendía de este modo cuando establece una comparativa entre la cama de su hogar y aquella clandestina de la calle Lafayette donde su marido recibía a sus amantes (Prévost, 1906a: 118). Una cama que simbolizaba, según la lógica discursiva de Prévost, la mentira de la unión conyugal en la que las mujeres quedaban maniatadas a la alterocentrista obligación de darse a los suyos por el bien de la familia ${ }^{15}$. De ahí que dormir sola en una cama propia no sólo era una liberación, sino un "auténtico placer".

Esta última idea podemos encontrarla en la confesión que, en Nouvelles lettres de femmes, realiza Mme Duclozac al manifestar abiertamente, en una carta dirigida a Mme Anquetin, que dormir sola en la cama de una misma era como volver a disfrutar de la libertad de la vida de soltera. Esta dama burguesa se sentía dichosa de haber recuperado los viejos hábitos de dormirse a una hora avanzada de la noche, vestirse conforme a como más cómoda se sintiera, leer y escribir echada sobre la cama, o tomar las posturas que mejor le vinieran para coger el sueño:

Sur la foi de ce subjonctif, je vivais paisible depuis deux ans et demi, j'avais repris toutes mes bonnes habitudes de jeune fille: de rôder en chemise dans ma chambre jusqu'à une heure avancée de la nuit, arrangeant mes petites affaires, relisant les vieilles lettres, en écrivant parfois; au lit, je feuilletais le roman qui me convenait jusqu'à l'heure où il me plaisait de dormir; puis, enfin, la lampe éteinte, je prenais sous ma couverture les attitudes les plus diverses, en long, en large, en rond, en diagonale, sans avoir de compte à rendre à personne. C'était délicieux. Vrai, les meilleures heures, sur les vingt-quatre, commençaient pour moi quand je poussais le verrou de ma chambre à coucher (Prévost, 1908b: 41).

En el momento en que Mme Duclozac echaba el cerrojo de su habitación, justo en ese preciso instante, dejaba de estar sujeta a todas aquellas voluntades ajenas que marcaban su conducta y determinaban quién debía ser. Era sólo entonces cuando ella podía ser libre, en su cama, en aquel lecho que concebía como la parte más diáfana de su identidad de mujer.

\footnotetext{
${ }^{15}$ Ese rol alterocentrista, que recibía también el sobrenombre de "bonne compagnie", como atestiguaba Pierre Boitard (1789-1859) en su Manuel-Physiologie de la bonne compagnie, du bon ton et de la politesse (1851), se fundamentaba en el hecho de que el ser buena madre y esposa primaba por encima de convertirse en una mujer intelectual, que, además, sirviera de apoyo al esposo. Esto implica que las mujeres a las que se alude en este estudio eran damas y señoritas burguesas instruidas, con la posibilidad de poder desempeñar cualquier profesión de las conocidas como liberales, pero con la carga de los preceptos morales, religiosos y tradicionales que las anclaba a un rol preconcebido.
} 
En concomitancia con esta experiencia, aunque no con tanto detalle, Dora Calvell, la semi-virgen cubana de Les demi-vierges, también declaraba —en este caso a su confidente, el pintor Valbelle - lo bueno que era dormir sola en la cama de una misma: "C'est si bon de dormir toute seule dans son lit !" (Prévost, 1907b: 120). Esta sentencia cobraba mucho más sentido viniendo de una "virgen a medias", cuya fama era la de evitar estar sola cuando se acostaba en su cama por las noches, y donde este enser cobraba la verdadera funcionalidad para la cual, según se dejaba entrever en la literatura prevostiana, había sido concebido, no siendo esta otra que la del sexo.

\section{CONCLUSIONES}

Con una trama perfectamente hilvanada, como se ha podido observar a lo largo del presente estudio, las funciones que se atribuían a la cama en los pasajes descritos por Marcel Prévost respondían siempre a una clara lógica conectiva. La estrategia de incorporar este instrumento en una acción determinada situaba al público lector en un punto concreto de la narración donde se avanzaba —o dejaba entrever- parte del mensaje que seguidamente iba a desprenderse del diálogo entre dos cónyuges o amantes o del simple soliloquio de uno de ellos. Dotar a este mueble de una amplia variedad de usos, dependiendo de las circunstancias que habían llevado a su aparición en el texto, convertían a la cama en un inteligente recurso desde el que poder construir el discurso literario. Un elemento que resultaba ser clave para la mise en scène de todo fragmento donde quisiera exponerse las relaciones sexuales de forma velada o sugerida. De este modo, sin abandonar el argumento del relato, una conversación entre dos amantes en una cama con las sábanas deshechas a plena luz del día inducía a pensar en una infidelidad recién consumada; el hecho de que un esposo tuviera un den instalado en el despacho no traía consigo más interpretación que la que, con ello, éste buscara tener sus aventuras amorosas en el mismo lugar donde desempeñaba su actividad profesional; el sueño profundo de una pareja en la que pudiera adivinarse el tenue rastro de las lágrimas secas sobre las almohadas era un claro indicio de una reciente reconciliación; la imagen de una mujer echada sobre una cama escribiendo o leyendo a altas horas de la noche era una de la más fidedignas muestras de la libertad femenina; la escena de una artista desvistiéndose, dejando entrever las gráciles parcelas de su piel desnuda mientras se preparaba para introducirse en la cama, contenía una alta carga de sensualidad; entre otros extractos igual de representativos. En todos estos episodios la cama se introduce como eje discursivo desde el que se crean conexiones entre sus variantes morfológicas y las secuencias que se forman a su alrededor.

Marcel Prévost se valió de los distintos significados que se concedían a la cama para ofrecer una panorámica de las costumbres de la burguesía parisina de su época, desvelando así las grietas y fisuras que existían en el constructo ideológico patrimonial. Los cánones conductuales atribuidos a los sexos, y muy especialmente a las damas y señoritas, no eran tan firmes como se creía, sobre todo en lo relativo al proceder de las 
mujeres. Si bien era habitual que los hombres fueran infieles, contrariamente a lo que pudiera creerse, sus esposas también siguieron este mismo comportamiento alejándose de esa intachable actitud alterocentrista de perfecta vestal que se esperaba de ellas. En ese sentido, el erotismo prevostiano, en tanto que modo de exaltar o provocar excitaciones de carácter sexual, no sólo ha de concebirse como psicológico, sino también interpretarse con ciertas connotaciones de índole social ya que recrea todas las prácticas relacionales de la época. A pesar de su propósito de regeneración moral, el escritor parisino nunca condenó a estas mujeres, sino que con sus relatos buscaba dar a conocer la existencia de esa "vida disoluta" de la que pretendía alejar a aquellas que todavía no habían caído en ella. Un erotismo moralizador que se generaba por reacción del opuesto, porque mostrando las acciones que en él acontecían a partir de un particular modelo de mujer - contrario al discurso dominante-, se conseguía apartar de ellas a las señoritas burguesas que en este modo de actuar no habían incurrido. Con todo, no hay evidencias de que el efecto moralizador que buscaba incardinarse en estas jóvenes tuviera el resultado deseado sobre su conducta, ni tampoco de que produjera el fenómeno contrario, es decir, que sirviera de acicate para que se comportaran como sus contramodelos de referencia.

En cualquier caso, es innegable que, en la producción literaria prevostiana, las camas fueron los testimonios de una geométrica confidencialidad, en la medida en que, aun tratándose de objetos inanimados, éstas parecían observar en silencio la amatoria prohibida de estas mujeres, sin emitir en este ejercicio reflexión alguna, ni tampoco juicio de valor. En la obra del autor francés son estos momentos los que sirven de ilación de un pasaje a otro, permitiendo al público lector conocer con mayor detenimiento el alma de sus protagonistas. La cama sirve de pasarela en el tránsito narrativo entre escenas, al igual que lo es el espacio donde este mueble de caleidoscópica funcionalidad se emplaza. Un escenario donde se desvelan los secretos de quienes sobre un lecho yacen, transluce la intimidad de sus espíritus y el ritmo de la historia se ralentiza para que estos individuos puedan amarse o descansar en un universo onírico creado por voluntad propia o por la sincera complicidad de dos.

\section{REFERENCIAS BIBLIOGRÁFICAS}

Angenot, M. (1983). "Des Romans pour les femmes: un secteur du discours social en 1889". Études littéraires 16.3, 317-350. Disponible en línea: https://www.erudit.org/fr/revues/etudlitt/1983-v16-n3-etudlitt2223/500619ar.pdf [17/11/2020].

Bataille, G. (1976 [1950-1951]). VIII. Euvres complètes de Georges Bataille. Paris: Gallimard. (Primera edición de 1950-1951).

Baudelaire, CH. (2006 [1857]). Las flores del mal. Edición bilingüe de Alain Verjat y Luis Martínez de Merlo. Madrid: Cátedra. 
Bertaut, J. (1904). Marcel Prévost. Paris: Bibliothèque Internationale d'édition.

Blandin, B. (2002). La construction du social par les objets. Paris: Presses Universitaires de France.

BOKOBZA KAHAN, M. (2000). Libertinage et folie dans le roman du $18^{e}$ siècle. LouvainParis-Sterling-Virginia: Peeters.

Clément, C. Y Kristeva, J. (2000 [1998]). Lo femenino y lo sagrado. Madrid: Cátedra.

CORBIN, A. (1998). Le temps, le désir et l'horreur. Essais sur le dix-neuvième siècle. Paris: Aubier.

LePAludier, L. (2004). L'objet et le récit de fiction. Rennes: Presses Universitaires de Rennes.

Luengo LóPEZ, J. (2016). “Actitudes y contingencias ante la libertad sexual femenina de un París de entresiglos (1880-1914)”. En Mujeres e Historia, C. Martínez López, A. Muñoz Fernández, M. M. Birriel Salcedo, J. Luengo López y C. Campos Luque, 121-169. Valladolid: Universidad de Valladolid / Instituto Universitario de Historia Simancas.

Maupassant, G. (1969 [1882]). Mademoiselle Fifi : Une vie. Paris: Gonon.

Petcoff, C. (1992). Le féminisme de Marcel Prévost ou l'art de la mystification. PhD Dissertation: McGill University.

Prevost, M. (1906a [1897]). Le jardin secret. Paris: Modern-bibliothèque. Arthème Fayard.

(1906b [1893]). L'automne d'une femme. Paris: Modern-bibliothèque. Arthème Fayard.

(1906c [1892]). Lettres de femmes. Paris: Modern-bibliothèque. Arthème Fayard. (1906d [1890]). Cousine Laura. Mœurs du théâtre. Paris: Modern-bibliothèque. Arthème Fayard.

(1907a [1901]). L'heureux ménage. Paris: Modern-bibliothèque. Arthème Fayard. (1907b [1894]). Les demi-vierges. Paris: Modern-bibliothèque. Arthème Fayard.

(1907c [1889]). Mademoiselle Jaufre. Paris: Modern-bibliothèque. Arthème Fayard.

(1908a [1902]). Lettres à Françoise. Paris: Modern-bibliothèque. Arthème Fayard.

(1908b [1894]). Nouvelles lettres de femmes. Paris: Modern-bibliothèque. Arthème Fayard.

(1909 [1897]). Dernières lettres de femmes. Paris: Modern-bibliothèque. Arthème Fayard.

(1911a [1901]). “Zabeau”. En Le domino jaune, M. Prévost, 95-97. Paris: Modernbibliothèque. Arthème Fayard.

(1911b [1901]). "La meurtre de Madame Aubry”. En Le domino jaune, M. Prévost, 79-83. Paris: Modern-bibliothèque. Arthème Fayard.

(s.a. [1912]). "La paille dans 1'acier”. En Missette, M. Prévost, 35-82. Paris: Modern-bibliothèque. Arthème Fayard. 
RoBIC, M. (2014). "La scène érotique en poésie autour du couple lesbien dans Les amies de Paul Verlaine". En La scène érotique sous le regard, F. Nicol et L. Perrigault (dirs.), 131-144. Rennes: Presses Universitaires de Rennes.

RoCHEFORT, F. (2003). "Assignations de genres dans Lettres à Françoise de Marcel Prévost”. En Aux frontières des deux genres. En hommage à Andrée Chedid, C. Boustani (dir.), 343-356. Bruxelles: Karthala.

VAlCÁRCEL, A. (2020). Pensar el feminismo y vindicar el humanismo. Mujeres, ética y política. Valencia: Universitat de València.

VAldivia Dounce, L. (2015). “El espejar y el retratar en la semántica de Frege”. Signos Filosóficos 17.34, s.p. Disponible en línea: http://www.scielo.org.mx/ scielo.php?script $=$ sci_arttext\&pid $=$ S1665-13242015000200078 [27/12/2020].

VÁZQUEZ JiMÉNEZ, L. (1996). "Le Sopha et ses conséquences Succès d'une esthétique de l'intimisme". En Songe, illusion, égarement dans les romans de Crébillon, J. Sgard (dir.), 79-92. Grenoble: ELLUG.

(2004). "La femme libre chez Voisenon". En Femmes et libertinage au XVIII siècle, A. Richardot (dir.), 77-85. Rennes: Presses Universitaires de Rennes. Disponible en línea: https://books.openedition.org/ pur/30551 [23/05/2021].

Velázquez EzQuerra, J. I. (2004). "Les demi-vierges, de Prévost: tres apuntes de análisis". En Palabras y recuerdos. Homenaje a Rosa María Calvet Lora, M. ${ }^{\mathrm{a}}$. Ozaeta, D. Popa-Liseanu y A. Yllera (dirs.), 219-225. Madrid: UNED.

El/la firmante del artículo se responsabiliza de las licencias de uso de las imágenes incluidas.

Fecha de recepción: 15/01/2021

Fecha de aceptación: 31/05/2021 